\title{
Alarma e defesa no ninho \\ de Synoeca surinama (L) (Hymenoptera: Vespidae) $\left(^{*}\right)$
}

\author{
E. G. Castellón (*)
}

\section{Resumo}

Relaciona-se neste estudo o comportamento social da comunicação durante o alarma e defesa do ninho de $\mathbf{S}$. surinama na presença de vespas $\mathbf{S}$. surinama de colônias diferentes e vespas Polistes canadensis. Incriminam-se aspectos visuais e feromônios como estímulos de excitação e ataque, e relacionam-se os fatores necessários para produzir alarma geral no ninho, como sâo: golpes sobre o invólucro e tempo de vibração das asas das guardiãs dos ninhos.

\section{INTRODUÇÃo}

Quando se causa um distúrbio nas proximidades do ninho, as vespas que comumente se encontram sobre o invólucro deste, adotam um comportamento de alarma que consiste em excitação, vibração repentina das asas e produção de som (golpes sobre o invólucro e zumbidos). A vibração das asas pode ou não estar acompanhada com a produção de som, de acordo com a intensidade de vibração. Em geral, insetos, pássaros ou qualquer outro animal podem aproximar-se do ninho. Se a distância de aproximação é relativamente grande (um metro ou mais) pode não haver excitaçāo. Entretanto, em alguns casos as vespas excitam-se e atacam nessá distância.

\section{MATERIAIS E MÉTODOS}

Para proceder às experiências, foram capturadas vespas $S$. surinama dos mesmos ni. nhos, S. surinama de outras colonias e vespas Polistes canadensis. Todos os indivíduos, vivos, foram amarrados pelo gaster com uma linha fina de $15 \mathrm{~cm}$ unida por outro extremo a uma vara de $2 \mathrm{~m}$ de comprimento. A exposição das vespas no invólucro em cada repetição foi de 1 (um) minuto. Em casos de ataque, podia. se prolongar a repetição até cinco minutos. Os graus de excitação, alarma e ataque são arbitrariamente qualitativos.

\section{RESUltados}

As vespas respondem geralmente à presença de insetos, a uma curta distância: até 10 ou $15 \mathrm{~cm}$ produzindo alarma no ninho. Dependendo da proximidade do intruso, do grau de agressividade e do número de vespas sobre o invólucro entre outros fatores, a resposta pode ser uma excitação individual ou coletiva. A excitação pode demorar até um máximo de 15 minutos. Quando uma vespa sobre o invólucro detecta a presença do intruso, produz-se a resposta individual, abrindo e cerrando as asas e levantando o abdome. A medida que abrem e cerram as asas, avançam rapidamente um trecho em linha reta ou em círculos, produzindo um zumbido com as asas, audivel a $5 \mathrm{~m}$ de distância. Durante o avanço, golpeam com a cabeça e asas as outras vespas excitando-as, as quais respondem com igual comportamento como as já excitadas. Este processo é lento como um sistema de comunicação de alarma entre os integrantes da colônia. Em geral, a excitação individual é rapidamente dissipada. A excitação é coletiva, quando a maioria das vespas sobre o invólucro detecta o intruso e responde simultaneamente, vibrando as asas $\mathrm{e}$ produzindo som e zumbidos mais fortes e coordenados que no caso individual. As vespas do interior do ninho respondem saindo ao invólucro, excitando-se e alarmando-se.

Existe um estado de alarma potencial permanente em alguns indivíduos do ninho que permanecem sobre o invólucro movendo as asas periodicamente. Quando uma ou várias vespas, daquelas consideradas potencialmente excitadas, movem as asas por exemplo, com a chegada de outras operárias ou pelo vôo de urn inseto nas proximidades do ninho, golpeam o invólucro produzindo 2 a 3 golpes por segundo. As vezes, o número de vespas potencialmente

(*) - Pesquisa financiada pelo INPA. Projeto Curso de Pós-Graduaçăo.

(*) - Instituto Nacional de Pesquisas da Amazônia, Manaus. 
excitadas pode chegar a dez produzindo duran. te este estado zumbidos e golpes sobre o invo. lucro sem chegar a produzir um alarma geral. Para produzir um elarma geral no ninho, tornam-se necessários os seguintes fatores:

1) Vibração das asas, produzindo zumbidos prolongados ( 3 a 4 vezes por segundo);

2) Golpes sobre o invólucro (possivelmente um dos fatores que mais influencia para produzir alarma geral entre os indivíduos da colônia.

A freqüência dos golpes normais para um indivíduo potencialmente excitado é de 2 a 3 golpes por segundo $N=15$ ). Entretanto, para produzir a excitação geral, o número de golpes é de 3 e 4 por segundo. Durante ambos, vibrações das asas e golpes sobre o invólucro, há avanços rápidos e periódicos sobre o invólucro. Os dois, tempo de vibração das asas e golpes sobre o invólucro, devem ser coordenados por todos os indivíduos que produzem. Estes fatores devem ser mantidos por um pe. ríodo superior a 5 segundos, tempo depois do qual as vespas que se encontram na abertura de acesso e no interior do ninho saem no invólucro, excitando-se e alarmando-se. As Tabelas 1,2 e 3 mostram resultados de experiências realizadas em ninho de $S$. surinama para observar o comportamento defensivo-agressivo dos indivíduos e sua capacidade para reconhecer operárias da mesma colônia e de colônias diferentes.

Dos resultados na Tabela 1, se depreende que em $55 \%$ dos casos, não existe excitação alguma ante a presença de vespas do mesmo ninho, em $35 \%$ das repetições apresentam pouca excitação, o que é no normal dado o grau de excitação potencial, exposto anteriormente e semelhante a quando pousa qualquer operária do mesmo ninho. Somente em duas repetiçōes

TABELA 1 - Comportamento de defesa de operárias de uma colônia com vespas da mesma colônia, amarradas e aproximadas do invólucro do ninho. Scm excitação = indiferentes. Pouca excitação $=$ reação ao vìbrar as asas (máximo 10 vespas). Alarma $=$ vibração das asas e golpes no invólucro, excitaçäo geral no ninho. Ataque no invólucro $=$ idem. Ataque em vôo $=$ saida em vôo das vespas para efetuar um ataque durante o mesmo. $(X)=$ Resposta positiva. $(-)=$ Resposta negativa

\begin{tabular}{|c|c|c|c|c|c|}
\hline \multicolumn{6}{|c|}{ Comportamento das operárias } \\
\hline Repetição & Sem excitação & Pouca excitação & Alarma & Ataque no invólucro & Ataque em vôo \\
\hline 1 & $x$ & - & - & - & - \\
\hline 2 & $x$ & - & - & - & - \\
\hline 3 & $x$ & - & - & - & - \\
\hline 4 & $\mathrm{x}$ & - & - & - & - \\
\hline 5 & $x$ & - & - & - & - \\
\hline 6 & $x$ & - & - & - & - \\
\hline 7 & $x$ & - & - & - & - \\
\hline 8 & - & $\mathrm{x}$ & - & - & - \\
\hline 9 & $x$ & - & - & - & - \\
\hline 10 & $x$ & - & - & - & - \\
\hline 11 & - & - & - & - & $x$ \\
\hline 12 & $x$ & - & - & - & - \\
\hline 13 & - & - & - & - & $\mathrm{x}$ \\
\hline 14 & - & $\mathrm{x}$ & - & - & - \\
\hline 15 & - & $x$ & - & - & - \\
\hline 16 & - & $x$ & - & - & - \\
\hline 17 & - & $x$ & - & - & - \\
\hline 18 & - & $\mathrm{x}$ & - & - & - \\
\hline 19 & - & $x$ & - & - & - \\
\hline 20 & $\mathrm{x}$ & - & - & - & - \\
\hline Total (20 rep.) & 11 & 7 & 0 & 0 & 2 \\
\hline Freq. & $55 \%$ & $35 \%$ & $0 \%$ & $0 \%$ & $10 \%$ \\
\hline
\end{tabular}


TABELA 2 - Comportamento das operárias de uma colônia de $S$. surinama ao aproximar vespas $P$. canadensis ao ninho. Sem excitação $=$ indiferentes. Pouca excitaçāo $=$ reação ao vibrar as asas (máximo 10 vespas). Alarma $=$ vibração das asas, golpes no invólucro, excitaçăo geral no ninho. Ataque no invólucro = idem. Ataque em vôo = saida em vôo de vespas $\mathrm{S}$. surinama para efetuar um ataque durante o mesmo. $(X)=$ Resposta positiva $(-)=$ Respos ta negativa

Comportamento das operárias

\begin{tabular}{|c|c|c|c|c|c|}
\hline Repetição & Sem excitaçāo & Pouca excitaçāo & Alarma & Ataque no invólucro & Ataque em vôo \\
\hline 1 & - & - & - & $x$ & - \\
\hline 2 & - & - & - & $x$ & - \\
\hline 3 & - & - & - & $x$ & - \\
\hline 4 & - & - & $x$ & - & - \\
\hline 5 & - & - & $x$ & - & - \\
\hline 6 & - & - & - & $x$ & - \\
\hline 7 & - & - & $x$ & - & - \\
\hline 8 & - & - & - & $x$ & - \\
\hline 9 & - & - & - & - & $\mathrm{x}$ \\
\hline . & - & - & - & $\mathrm{x}$ & - \\
\hline 11 & - & - & - & $x$ & - \\
\hline 12 & - & - & - & $\mathrm{x}$ & - \\
\hline 13 & - & - & - & - & $x$ \\
\hline 14 & - & - & - & - & $x$ \\
\hline 15 & - & - & - & $x$ & - \\
\hline 16 & - & - & - & $x$ & - \\
\hline 17 & - & - & $\mathrm{x}$ & - & - \\
\hline 18 & - & - & - & $\mathrm{x}$ & - \\
\hline 19 & - & - & $x$ & - & - \\
\hline 20 & - & - & - & - & - \\
\hline Total (20 rep.) & 0 & 0 & 5 & 11 & 4 \\
\hline Freq. & $0 \%$ & $0 \%$ & $25 \%$ & $55 \%$ & $20 \%$ \\
\hline
\end{tabular}

(respectivamente 11 e 13 que correspondem a $10 \%$ do total) a vespa cativa foi atacada a uma distância de cerca de $10 \mathrm{~cm}$ e uma vez que a vespa cativa pousou sobre o invólucro, cessou 0 ataque. Possivelmente, o ataque inicial é produzido por um estímulo visual. Em 90\% das repetições, as vespas puderam reconhecer o animal cativo como do mesmo ninho por sua aceitação sobre o invólucro, o que indica que existe alguma substância (feromônio) comum a todos os integrantes da colônia e que permite seu reconhecimento e aceitação no ninho.

Nas 20 repetições com $P$. canadensis, em $100 \%$ dos casos, foram rechaçadas pelas operárias de S. surinama do ninho (tabela 2), sen do que em $25 \%$ dos casos houve alarma geral evitando que a cativa pousasse sobre o invóluvro (e também $P$. canadensis evitava aproximar-se do ninho). Em $55 \%$ dos casos, houve ataque sobre o invólucro e em $20 \%$ houve ataque em vôo. $\mathrm{O}$ ataque foi realizado por uma média de 4 vespas $(3-5 ; N=15)$. Estes ataques podiam durar de 30 segundos a um minuto. Durante o ataque, as operárias de S. surinama mordiam as asas, patas e antenas da $P$. canadensis cativa. O comportamento de alarma variou, consistindo na detecção do intruso pelas operárias que atacam; logo depois do ataque e posterior fuga do intruso, davam o alarma geral que podia prolongar-se por 10 segundos; as vespas mais excitadas e alarmadas podiam prolongar este estado por 10 minutos. Quando o alarma antecede ao ataque, como parece ser o procedimento normal, as vespas podem ata. car em maior número (excitação coletiva e alarma geral) sendo que o período não passa de 10 segundos e as vespas mais excitadas prolongam-no por 10 minutos. 
Para que exista um clímax de excitação $e$ alarma, é necessário que os fatores de produçāo do alarma, mencionados anteriormente, prolonguem-se por um período superior a 15 segundos. A duraçāo do estado de alarma pode ser de 15 ou mais minutos. Esta mesma descrição sobre 0 ataque se aplica para as $S$. surinama capturadas em outros ninhos. Os resultados com as vespas da mesma espécie, porém de ninhos diferentes (Tabela 3 ), mostram que em $10 \%$ das repetições existiu alar$\mathrm{ma}$, em $55 \%$ houve ataque sobre o invólucro e em $35 \%$ houve ataque em vôo fora do ninho.

Com distúrbios bastante fortes no ninho, por exemplo, golpes sobre o invólucro, danos do ninho e distúrbios da árvore substrato, quase que imediatamente as vespas tanto sobre o invólucro como do interior do ninho respondem voando em círculos de $2 \mathrm{~m}$ de diâmetro ao redor do ninho, pousando sobre o invólucro 7 a 10 segundos mais tarde. Todos os individuos, depois do distúrbio, permanecem por longo tempo excitados e alertas caminhando sobre o invólucro quase ininterruptamente.

Em ninhos que estavam em construção e cujo invólucro ainda não tinha sido construído, as vespas ao detectar um intruso, somente podiam produzir som por vibração das asas, podiam também golpear a cabeça e corpo de outras operárias sem contudo excitá-las. Este fato é uma evidência para demonstrar que devem interagir os fatores para ser produzido um estado geral de alarma no ninho. Portanto, o estado de alarma-agressividade-defesa estará diminuído sempre que faltar um dos fatores para produzir alarma geral no ninho.

TABELA 3 - Comportamento das operárias de S. surinama com vespas da mesma espécie porém de colônias diferentes, enlaçadas e aproximadas ao invólucro. Sem excitação $=$ indiferentes. Pouca excitação $=$ reação ao vibrar as asas (máximo 10 vespas). Alarma = vibração das asas, golpes no invólucro, excitaçăo geral no ninho. Ataque no invólucro $=$ ídem. Ataque $\mathrm{em}$ vôo $=$ saída $\mathrm{em}$ vôo das vespas $\mathrm{S}$. surinama para efetuar um ataque durante o mesmo. $(X)=$ Resposta positiva. $(-)=$ Resposta negativa

Comportamento das operárias

\begin{tabular}{|c|c|c|c|c|c|}
\hline Repetição & Sem excitação & Pouca excitação & Alarma & Ataque no invólucro & Ataque em vôo \\
\hline 1 & - & - & $x$ & - & - \\
\hline 2 & - & - & - & - & $x$ \\
\hline 3 & - & - & - & $\mathrm{x}$ & - \\
\hline 4 & - & - & - & $\mathrm{x}$ & - \\
\hline 5 & - & - & - & - & $\mathrm{x}$ \\
\hline 6 & - & - & - & - & $x$ \\
\hline 7 & - & - & $x$ & - & - \\
\hline 8 & - & - & - & $x$ & - \\
\hline 9 & - & - & - & $\mathrm{x}$ & - \\
\hline 10 & - & - & - & - & $x$ \\
\hline 11 & - & - & - & $x$ & - \\
\hline 12 & - & - & - & $x$ & - \\
\hline 13 & - & - & - & - & $\mathrm{x}$ \\
\hline 14 & - & - & - & $\mathrm{x}$ & - \\
\hline 15 & - & - & - & $x$ & - \\
\hline 16 & - & - & - & $x$ & - \\
\hline 17 & - & - & - & - & $x$ \\
\hline 18 & - & - & - & $\mathrm{x}$ & - \\
\hline 19 & - & - & - & - & $\mathrm{x}$ \\
\hline 20 & - & - & - & $x$ & - \\
\hline Total (20 rep.) & 0 & 0 & 2 & 11 & 7 \\
\hline Freq. & $0 \%$ & $0 \%$ & $10 \%$ & $55 \%$ & $35 \%$ \\
\hline
\end{tabular}


Dos resultados das Tabelas 2 e 3 depreende-se que as vespas $S$. surinama têm a capacidade de distinguir visualmente e também por feromônios os individuos que podem ser invasores ou inimigos do ninho e diferenciá-los dos indivíduos da mesma colônia.

\section{DISCUSSÃo}

A comunicação de alarma é empregada, de uma forma ou outra, entre os grupos superiores de insetos sociais e tem o efeito de atrair as operárias até a fonte de perigo para assim proteger as rainhas, crias e outras formas potencialmente reprodutoras (Wilson, 1974). Esta co. municaçâo dá-se em todos os himenópteros eusociais, e Michener (1953) considera que a eusociabilidade em insetos leva a certas vantagens, uma sendo a defesa especialmente das formas reprodutoras. O comportamento de alarma e defesa do ninho de $S$. surinama é similar ao descrito por Akre et al. (1976) para Vespula pennsylvannica (Sauss.) e V. atropilosa (Sladen) e por West-Eberhard (1969) para Polistes fuscatus, onde algumas operárias ocupam uma posição de alerta no ninho e, quando excitadas pela presença de intrusos, há alarma e vibração das asas e ataque. West-Eberhard (1969) descreveu a vibraçāo das asas como um componente do sinal de alarma em Polistes.

Existe um reeonhecimento dos individuos do mesmo ninho, o qual é atribuído a odores característicos no ninho que condicionam os indivíduos de uma mesma colônia para o reconhecimento interespecífico. Estes odores podem ser percebidos por todos os indivíduos da colônia e em especial pelas vespas operárias que adotam uma postura de guarda no ninho. A ação das guardiāes é admitir ou repelir a presença de outros indivíduos nas proximidades do ninho ou neste e a proteção das crias e das rainhas. Face a isto, certas fêmeas são muito mais agressivas que outras e podem facilmente ser excitadas (Barrows, et al., 1975; Akre et al. 1976; West-Eberhard, 1969). Evans e West-Eberhard, (1970 apud Richards, 1971) dizem que entre os feromônios existem substâncias de alarma, havendo certas evidências de sua presença e sua funçăo é alertar o ninho do periga.
Em S. surinama, além de existir reconhecimento interespecifico, por meio de odores para aceitar ou rechaçar os individuos da mesma colônia, existe um reconhecimento visual, à distância, que colabora para produzir o alarma Uma vez que conseguem detectar a presença do inimigo, o ataque é produzido, no que inte ragem fatores como movimentos e vibração asas, avanços rápidcs e produçãc de sons devidos a golpes sobre o invólucro. A consistência do invólucro, então, é também importante na comunicação dos individuos para produzir o alarma; Skutch (1959) opinou que o papelāo do invólucro ałua como uma caixa de ressonância que intensifica à produção do som.

Trabalho sobre comunicação do alarma e defesa do ninho foram escritos por Jeanne (1972, 1975). Richards \& Pichards (1951). Wilson (1974) e Skutch (1959), onde analisam os fatores de alarma e o comportamento de defesa.

Michener (1953) considerou que a comunicação está relacionada com a vida de todos os insetos, em muitas ordens, particularmente nos himenópteros que usam feromônios como meio de comunicação entre os individuos de uma colônia. Entre os insetos não sociais os feromônios têm entre outras funçōes as de atrair individuos do sexo oposto, e alarma (Borrows. et al. 1975).

\section{CONCLUSÕES}

O comportamento de alarma e defesa do ninho de $S$. surinama está coordenado por fatores visuais e por meio de odores, existindo um reconhecimento interespecífico entre individuos da mesma colônia.

Estes fatores em conjunto na presença de intrusos incitam e produzem o ataque das vespas.

\section{AGRAdeCIMENTOS}

Agradeço ao CNPq-INPA-MPEG pela colaboração e financiamento desta pesquisa. Ao colega Miguel Petrere Jr., ao Dr. Robert L. Jeanne, ao Sr. Nelson e à Sra. Francisca, pela ajuda que prestaram. 


\section{SUMIMARY}

This study concerns to the social communication of S. surinama during alarm and nest defense. Visual and pheromone responses are incriminated as stimulants of excitation and attack, and are related to the factors necessary to produce general alarm in the nest, as are: rate of wings vibration of nest guards and blows to the involucre.

\section{REFERENCIAS BIBLIOGRAFICAS}

AKRE, R.D.; GARNETT, W.B.; MacDONALD, J.F.;

GREENE, A.; LANDOLT, P.

1976 - Behavior and colony development of Ves. pula pennsylvannica and $\mathbf{V}$. atropilosa $(\mathrm{Hy}-$ menoptera: Vespidae). J. Kans. Entomol. Soc., 49 (1): $63-84$

BARROWS, E.M.; BELL, W.J.; MICHENER, C.

1975 - Individual odor diffrerences and their social functions in insects. Proc. Nat. Acad. Sci USA, 72 (7): $2824-2828$.

JEANNE, R.L.

1972 - Social biology of the neotropical wasps Mis. chocyttarus drewseni. Bull. Mus. Comp. Zoo., 144 (3): 63-150.
1975 - Behavior during swarm movement in Stelo. polybia areata (Hymenoptera: Vespidae) Psyche, 82 (2): 259-264.

MICHENER, C.D.

1953 - Problems in the development of social behavior and communication among insects. Trans, Kans, Acad. Sci., 56: 1-15

RICHARDS, O.W.

1971 - The biology of the social wasps (Hymenop tera: Vespidae). Biol. Rev., 46: 483-528

RICHARDS, O.W. \& RICHARDS, M.J.

1951 - Observations on the social wasps of South America (Hymenoptera: Vespidae). Trans R. Ent. Soc. Lond., 102 (1): 1-169.

SKUTCH, A.F.

1959 - The scourge of the wasps, Animal Kingd, 62: 8-13.

WEST, EBERHARD, M.J.

1969 - The social biology of Polistine wasps. Misc. Publ. Musc. Zool. Univ, Michigan, 140: 1-101.

WILSON, E.D.

1974 - The insect Societies. Harvard Univ. Press. Cambridge, Mass. $x+549 p$.

(Aceito para publicação em 01/07/80) 